ESJ Humanities

\title{
Intercultural Communication Challenges in the Period of the Novel Coronavirus (Covid-19) (The Case of Qatar Airways)
}

\author{
Margo Kublashvili, PhD student
}

Ivane Javakhishvili Tbilisi State University, Tbilisi, Georgia

Doi:10.19044/esj.2021.v17n16p1

Submitted: 13 April 2021

Accepted: 24 May 2021

Published: 31 May 2021
Copyright 2021 Author(s)

Under Creative Commons BY-NC-ND

4.0 OPEN ACCESS

Cite As:

Kublashvili M. (2021). Intercultural Communication Challenges in the Period of the Novel Coronavirus (Covid-19) (The Case of Qatar Airways). European Scientific Journal, ESJ, 17(16), 1. https://doi.org/10.19044/esj.2021.v17n16p1

\section{Abstract}

Under the conditions of the global threat of the modern world - the novel coronavirus (Covid-19) pandemic, the demand for social distancing as a commonly proven method of preventing fatal cases and stopping the virus has fundamentally changed the process of communication in an intercultural environment. Our research aims to study the impact of the pandemic on the intercultural communication process and its quality in a multicultural environment. Cabin Crew of Qatar Airways, as one of the largest multicultural/multinational companies, was selected as a target group. A qualitative method of data collection - interviewing - was used as a research technique. In particular, the target group was interviewed through a semistructured questionnaire - by a so-called "narrative interview" method. This research enabled us to obtain new narratives which were created on the coronavirus background - responses of the Qatar Airways Cabin Crew and the company's international passengers to the challenge of Covid-19. The study and analysis of these responses revealed that representatives of different cultures (Individualistic/Collectivist cultures, High/Low uncertainty avoidance cultures, Submissive orientation/Mastery orientation cultures, Tight/Loose cultures) have different attitudes towards the pandemic as an uncertain and unpredictable future; towards the Covid-19 vaccine; towards wearing a mask and eye contact related to it; in addition, they can be distinguished by different perceptions of territorialism as personal space (physical and social distancing); different feelings of fear and anxiety and readiness to obey/disobey introduced rules or restrictions (so-called 
Lockdown, Curfew). According to the research, these differences are due to the "mental program" of a society, i.e. a purely cultural factor. However, despite several intercultural differences, daily contact with groups having other cultures significantly increases opportunities for collaboration, which, in times of crisis, does not hinder the process of interaction between different cultures, but on the contrary, it increases the level of intercultural acceptance and sensitivity.

Keywords: Intercultural communication, multi-ethnic workplace, communication challenges, cultural differences, Qatar Airways, Covid-19

\section{Introduction}

The World Health Organization (WHO) officially declared Covid-19 (the novel coronavirus) as a global pandemic on March 11, 2020. The threat of physical destruction, international tension, stress, economic problems caused by the pandemic, fear of an unpredictable and uncertain future created a new reality, which in turn was followed by a change in the usual rhythm/routine of human life and the need of adapting to the pandemic.

Against the background of the novel coronavirus pandemic, social distancing has become the most frequently used term in the world and has been announced as the only means of physical survival and overcoming the crisis. Most local and international companies, within the frameworks of possibility, have switched to virtual work mode. The challenge has been particularly difficult and critical for airlines, the virtual operation of which is impossible, and in the conditions of remote restrictions, according to the International Air Transport Association (IATA), this sector has seen unprecedentedly large losses - revenue, compared to 2019 , decreased by $50 \%$ (this is a daily loss of about $\$ 230$ million). ${ }^{1}$ Qatar Airways was no exception. At the beginning of the pandemic, the number of its flights dropped from 180 to 30 and according to the data of October 14, as a result of the use of effective methods of crisis management, it gradually increased to 85 .

The requirement of social distancing as a commonly proven method of preventing fatal cases and stopping the virus in pandemic conditions has naturally led to the restriction of close physical contact and face-to-face interaction, which has significantly hindered the communication process in the intercultural environment, and precondition of its management is triggered by one's desire and motivation to perceive novelty. In the pandemic conditions, common proclamations and words such as "stay home," "isolation," "selfisolation," "physical distance" have automatically aggravated subconscious

\footnotetext{
${ }^{1}$ See Industry Losses to Top $\$ 84$ Billion in 2020, https://www.iata.org/en/pressroom/pr/202006-09-01/ (was available on 24.10.2020).
} 
fear towards others (especially if it is a representative of a foreign/other culture) and reduced (or in some cases have annihilated) desire, willingness or motivation to communicate with others. Moreover, this phobia has even led to a racist-xenophobic problem.

Indeed, the spread of the novel coronavirus from China all around the world has led to a deepening of racial discrimination. At the initial stage of the virus outbreak, (during the news about Wuhan Province) increase in fear and disgust towards Chinese people was obvious. Several cases of distancing from them and expressing distrust were revealed in America, Canada, Britain, France, Georgia, and other European countries. ${ }^{2}$ The existence of this discrimination is confirmed by the fact that Chinese people living in different countries started using a new hashtag - "I am not a virus" - on social networks. Moreover, the world leader, the US President of that time Donald Trump, officially accused China of delaying the spread of information concerning the coronavirus and used the phrase "a war against Chinese virus" while talking about the virus.

Of course, separation, expulsion and restriction of people based on such national or ethnic affiliation appear to be a hindering condition in the process of intercultural communication. Within the interests of the research, it was important for us to monitor and analyze the existing threat on the example of Qatar Airways as one of the largest multicultural/multinational companies. All the more, one of the largest groups of employees of the latter is of Chinese origin.

Research actuality. As it is known, intercultural dialogue is a constant and uninterrupted process. Consequently, the interest in it is always great. The urgency and importance of the research problem are even clearer today, in the context of the global threat of the modern world -the novel coronavirus when the pandemic once again made us see it clearly that xenophobic and racial discrimination remain a major challenge. As for the intercultural dialogue, it is the only means to overcome a new wave of this threat, to reduce intercultural barriers and uncertainties between different groups and individuals, and to achieve peaceful and harmonious coexistence in times of global crisis.

Research purpose. This research aims to study and analyze different cultural attitudes (responses) towards the Covid-19 challenge and to determine the importance of intercultural dialogue and its practical values in times of crisis. In particular, we will try, in the frameworks of the multicultural

\footnotetext{
${ }^{2}$ See Coronavirus: What attacks on Asians reveal about American identity, https://www.bbc.com/news/world-us-canada-52714804; Londoners 'experiencing racism over coronavirus', https://www.bbc.com/news/av/uk-england-london-51361930; Prejudice toward Asian Americans in the Covid-19 Pandemic https://www.frontiersin.org/articles/10.3389/fcomm.2020.00039/full (was available on 24.10.2020).
} 
workplace, to observe the impact of the pandemic as a global phenomenon on the process of intercultural communication, on the example of Qatar Airways, to identify the resulting problems or communication barriers, and finally identify necessary skills and abilities for working in such an unusual, turbulent working environment and practical recommendations.

Research hypothesis. The main part of our research serves to examine the following hypothesis: the pandemic significantly hinders the process of interaction between different cultures in a multiethnic workspace and increases the level of intercultural uncertainty, which in global terms will contribute to further escalation of intercultural conflicts and a new formation of the post-pandemic world - world deglobalization. as follows:

Research Questions. Our main research question may be formulated

What is the impact of the pandemic on the process of intercultural communication and on its quality in Qatar Airways?

It can be divided into several sub-questions:

To what extent do pandemic conditions impede interaction of the Cabin Crew (desire for intercultural communication, readiness, or motivation) while communicating on the one hand with the colleagues and, on the other hand with customers/passengers of the company?

Is the change in racist-xenophobic attitudes towards a particular ethnic group (Chinese) visible (both at the beginning of the pandemic and in its later phase)?

Finally, we are also interested in what exact changes the coronavirus pandemic has made.

Research method. There is the qualitative method of data collection - interviewing - used in the paper, which is one of the most widely used ways of obtaining the information. In particular, we questioned the target group through a semi-structured questionnaire, by the so-called "narrative interview" method, which was carried out via the "Google Hangout" special software. The fact that I, as a former Qatar Airways flight attendant, still have a direct and close relationship with my former colleagues, the current employees of the company, helped us to carry out and conduct this interview effectively.

Using this method, the research enabled us to obtain new narratives created against the background of the novel coronavirus, detailed, deep, and consecutive information on ideas and personal experience of the target group. All this, in turn, contributed to a more accurate study and analysis of the research issue.

Literature review. The conceptual framework of the research is based on theories of cultural typology. For the determination of the direction and theoretical framework of our research, one of the earliest models of the cultural 
typology, which was developed by the well-known American anthropologist Edward Hall, is particularly important. In his book "The Silent Language", Hall introduces one of the main criteria of cultural typology - territorialism, an unconscious attitude towards space that is sharply different in different cultures (Hall 1959: 187). Later, in his work "Understanding Cultural Differences", Edward Hall together with his wife, Mildred Hall, discuss the importance of personal space in the process of intercultural communication even in more detail. In particular, he talks about an invisible protective circle that constantly accompanies a person, and shows an appropriate distance between another person, which changes (decreases or increases) according to circumstances and attitudes towards the people around (Hall and Hall 1990: $11)$.

Another very important author, the Dutch psychologist Geert Hofstede, formulates in his work, "Cultures and Organizations. Software of the Mind", the theory of cultural dimensions, according to which a person with a certain culture is provided with a preliminary mental program. This program contains a national element, i.e. a component of the culture in which this person was born and raised (Hofstede, Hofstede and Minkov 2010: 5-6). Therefore, different cultures have different dimensions, different directions, and attitudes towards time and space, individuals and groups, power, tradition, novelty, etc. These different dimensions, of course, affect intercultural communication.

The fourth dimension separated by Hofstede in the early 1970s based on the results of the research carried out in IBM, one of the largest multicultural companies in the world is especially interesting for us. In particular, Hofstede's research showed that cultures with a high Uncertainty Avoidance Index (UAI) try to predict the future and therefore to control events, and in countries where this index is weak, society is more relaxed and less anxious about what will happen and how it will happen. The latter ones are cautious about formal rules and believe that they should apply them only in case of extreme necessity, although, if they apply them, they follow them better (Hofstede, Hofstede and Minkov 2010: 209-210).

Different approaches of the individualistic and collectivist cultures to the pandemic are also interesting for us. Therefore, we actively used Hofstede's second dimension in the process of the research (Individualism versus Collectivism (IDV)). According to Hofstede's explanation, a society in which the interests, lifestyle, or views of an individual are separated from the opinions/ideas of other members of the same culture and he/she stands above the group interests, is an individualistic society. A member of this society identifies himself/herself as "I", in contrast to a collectivist society, in which "we" is the main precondition for the need to differentiate from the "other" and for protection, in which "we", or the group, defines an individual's 
consciousness and action (Hofstede, Hofstede and Minkov 2010: 90-91). Hofstede's research showed that the existence of these two opposing dimensions in intercultural communication poses a risk not only of inconvenience and minor misunderstandings but also of a serious crisis in international business.

In the process of the qualitative research, we also used Kluckhohn and Strodtbeck's Values Orientation Theory of cultural studies, which meant the comparison of cultures based on human attitudes towards the universal issues that are related to the habits of human nature, attitudes towards time, nature, activities, each other (Kluckhohn and Strodtbeck 1961: 10-12; Hills 2002: 4-5). By using this method, we tried to study the existing attitudes towards Covid-19 in different cultures. In particular, how different cultures respond/deal with the problems and stressful situations caused by the novel coronavirus.

Following the context of our research, we are also interested in how attitudes towards the threats and crises posed by the pandemic are different in different cultures. In this regard, we are interested in the Cultural Theory of Risk, developed by British-American anthropologist Mary Douglas in the late 1960s and later developed by her together with Aaron Wildavsky. From their point of view, the perception of risk and threat and people's reaction to them are stipulated by a purely cultural factor. Therefore, they are different in different cultures (Douglas, 1978; Douglas \&Wildavsky, 1982; Douglas, 1992).

The above-mentioned theories of the cultural typology represent the main theoretical basis of our paper, allowing me to observe the most important process of intercultural communication from different angles and to understand it about modern challenges (the novel coronavirus pandemic).

\section{Data collection}

Data collection method. As it was mentioned in the introduction, the qualitative method of data collection - interviewing - was used as the research technique. As we were interested in the subjective knowledge, experience, practice, motivation, mood, and attitudes (i.e., what is not expressed through a standardized questionnaire) of the phenomenon under the observation, the target group was interviewed through a semi-structured questionnaire - by the so-called "narrative interview" method, which was carried out via the special software "Google Hangout".

Research participants. A determining factor in the selection of the research participants became the multiethnicity of the workspace, and the Cabin Crew of Qatar Airways, as one of the largest multicultural companies, was selected as the target group. It should be mentioned that the respondents were selected not randomly, but purposefully, on the principle of national 
quota selection. In particular, the target group was separated based on ethnicity and 25 flight attendants of different nationalities (namely, Indian, Filipino, Japanese, South Korean, Moroccan, French, German, Spanish, Serbian, Romanian, Macedonian, Georgian, Argentinean, and Brazilian) and 10 Chinese (including 3 Hongkongers) were selected for the interviewing.

Sample of the research questionnaire and description of data collection process (interviewing). Obtaining the desired information became possible based on the semi-structured questions. In particular, a discussion plan was developed in advance, i.e., a written outline of the possible questions and their desired sequence, which helped us to control the process of interviewing. The in-depth interview was carried out based entirely on openended questions and contained questions measuring attitude/mood and questions of behavioral/psychographic types on the topic of our interest.

It should be mentioned that the process of interviewing was voluntary, its purpose was disclosed in advance, and therefore each respondent knew that we were carrying out a doctoral research on revealing the main problems and barriers created in intercultural communication during the pandemic and the ways of overcoming them.

The first question that was asked to all respondents was sentimental and aimed to create a general idea of the respondent's attitude to the issue that is important to us - what is the impact of the pandemic on the communication process. The questions around this issue were formulated as follows. What was the main challenge that they had to face in obeying the norms and regulations introduced based on the novel coronavirus (for example, "physical distancing" while being on board, where it is difficult and sometimes impossible to fulfill)? Here we were interested in how much the preCoronavirus desire and motivation to interact with the "other" had changed (decreased or completely disappeared). Also, to what extent the conditions of the pandemic hindered communication - on the one hand, with the colleagues (Cabin Crew and other employees of the company) and, on the other hand, with the company's international customers/passengers. Also, in the process of the interviewing, we spoke about word associations related to the workspace that emerged due to the Covid-19. To go deeper into the issue, during the discussion we asked the respondents to reinforce their opinions with certain examples.

It was essential for us to discuss the issue of racial discrimination against the background of the novel coronavirus and to show the existing challenge on the example of Qatar Airways, one of the largest ethnic groups whose staff, as it was mentioned above, is Chinese origin. In particular, we were interested in how noticeable the change in attitudes and xenophobic approach towards Chinese was both at an early stage of the coronavirus outbreak (at the time when the news about Wuhan was topical) and at a later 
stage of the virus. Therefore, the following sub-questions were asked during the interviews. Were there any specific facts of discrimination revealed while communicating with Chinese passengers or Chinese colleagues? Has the degree of racial discrimination changed - has xenophobic fear and distrust towards this particular ethnic group become deeper or vice versa, weakened or completely disappeared? In this context we had the following additional psychographic questions to the Chinese respondents: have they had any moments of embarrassment and self-exculpation while communicating with colleagues and passengers during the work process/flight? Have they felt any kind of judgmental attitude from colleagues or passengers of other nationalities?

The third, concluding part of the interview aimed to find out the respondents' evaluative attitude - what are their prejudices and predictions/expectations (negative or positive) about the new post-pandemic arrangement of the world. In the same context, we asked the following subquestions. What have they learned, what experience have they achieved from the coronavirus pandemic? What have they changed? What have they reevaluated?

As it was mentioned above, a total of 35 respondents were interviewed, most of them had more than 5 years of work experience. The first interview was held on October 30, 2020, the last - on December 5 of the same year. The interviewing process lasted for about 40-50 minutes (15 minutes on average were reserved for each question). At the interview, to visualize the data, transcripts of the obtained empirical material were coded, so to say "decrypted".

\section{Data Processing and Analysis}

As we have already mentioned, the requirement of social distancing has become a commonly proven method of preventing fatal cases and stopping the virus in pandemic conditions, which has naturally led to the restriction of close physical contact and face-to-face interaction between people. Following the WHO recommendations and obeying the rules and regulations introduced by IATA directly for airlines for conducting and regulating the communication process $^{3}$, Qatar Airways declared the following as mandatory:

1. Wearing a face mask during the flight (it should be mentioned that Qatar Airways provides all passengers with protective equipment and

\footnotetext{
${ }^{3}$ See Guidance for Cabin Operations During and Post Pandemic Edition 4 - 08 Sep 2020, https://www.iata.org/contentassets/df216feeb8bb4d52a3e16befe9671033/iata-guidancecabin-operations-during-post-pandemic.pdf; Guidance for Crew Health Precautions During Pandemic Edition 1 - 28 May 2020, https://www.iata.org/contentassets/df216feeb8bb4d52a3e16befe9671033/iata-guidancecrew-health-precautions-during-post-pandemic.pdf
} 
offers a so-called protective kit, which includes a mask, gloves, and hand sanitizer);

2. Wearing a full-face mask (so-called face shield) during check-in, boarding and disembarkation, even during being on board of economy class (except mealtime);

3. For Cabin Crew - Personal Protective Equipment gowns, PPE, wearing special goggles and gloves;

4. Social distancing during check-in - no less than 1.5 meters, and during being onboard - minimum 1 meter (within maximum possibilities);

5. Identifying each passenger as potentially infected and limiting the contact time of a flight attendant with him/her (up to a maximum of 10 minutes) and even only in case of urgent need (e.g., mandatory service and first aid, dealing with uncontrolled/rude passengers, for example, when they do not want to wear masks);

6. Minimal interaction between flight attendants, rational restriction of contact with the captain and the first officer, being in their positions during most of the flight. (It should be mentioned that each flight attendant onboard has his/her zone identified and allocated in advance, taking into consideration the configuration of the plane and his/her position. A flight attendant can be the right or the left-wing L1 / R1, L2 / R2, L3 / R3, etc. member of the Cabin Crew);

7. Maximum restriction of passengers' movement and strict monitoring on it.

The requirement to obey the mentioned norms and regulations has, of course, substantially changed the usual process of communication at Qatar Airways. Our first goal while interviewing was to understand the respondent's attitude towards these changes. By classifying the received answers to our question - what is the impact of the pandemic on the process of communication and how difficult it is to work with the norms and regulations introduced due to the coronavirus - we can conclude that this is an unusual condition accompanied by fear and stress of uncertainty towards an unknown and unpredictable pandemic situation. At the same time, studying and observing the responses towards the pandemic have demonstrated varying degrees of attitudes towards uncertainty and anxiety in different cultures.

Indeed, as social anthropologists Mary Douglas and Aaron Wildavsky point out, the perception of risk and threat as well as how people react to them are connected to the fear of an uncertain/unknown future and the feeling of anxiety and are mirrored by a purely cultural factor. What is perceived as a threat and is considered dangerous depends on the cultural and social affiliation of an individual and is therefore different in different cultures (Douglas, 1978; Douglas \&Wildavsky, 1982; Douglas, 1992). 
While studying this issue, the fourth dimension which was pointed out based on the results of the research carried out in IBM by Geert Hofstede Uncertainty Avoidance Index (UAI), the level of which (high or low) - is connected to the feeling of fear and anxiety towards an unknown future and, according to Hofstede, it is mirrored by a certain society, family, school and a common, mental program of adult life (Hofstede, Hofstede and Minkov 2010: 189-190).

The example of the interviewed Cabin Crew's answers also showed that the attitude of a certain number of flight attendants towards the ambiguous Covid situation is particularly stressful, impulsive, and anxious. Cultures characterized by high levels of anxiety are also expressive cultures, which are characterized by sharply expressing their emotions, raising voice, showing more aggression, being restless, etc. (Hofstede, Hofstede and Minkov 2010: 196). It was obvious even from the tone of the voice and narratives of our respondents: If Spanish, Romanian and Brazilian flight attendants are particularly anxious when speaking about working in the pandemic conditions, unlike them, Chinese, Japanese, Korean, or Filipino flight attendants are calmer and less emotional while speaking.

According to Sarah, a flight attendant from Spain: "either nobody speaks on board or if anybody speaks the topic of the conversation is about pandemic. This silence is unbearable ... you want to take off your mask, take a deep breath and talk to the passengers, your colleagues about something, even uninteresting things, like it was in the past... Expectation of spending a pleasant layover has been replaced by being locked in a cold hotel room, by anxiety and a feeling of constant tension ... the worst part is that the end of it all is unknown". While speaking about the same problem, the voice of my Japanese friend Kumiko is calmer, the level of anxiety is lower; her answer to the current challenge is not impulsive; it seems like this "unusual" state is less important for her; of course, she sees the threat, though she suffers less because she knows that she will follow the rules and everything will be all right.

In the novel coronavirus pandemic conditions, a high index of uncertainty avoidance is directly related to a particular need for social distancing and is expressed by a lack of willingness to communicate with others, although it does not always imply a high degree of anxiety. Vivid examples of this are Japan and South Korea, which Hofstede, unlike other Asian countries (for example, Singapore, China, India, Thailand, Malaysia), included in the list of countries with a high index of uncertainty avoidance, but also, as an exception, as the countries with low index, he described them as countries with a low degree of anxiety and without impulsivity (Hofstede, Hofstede and Minkov 2010: 195-197). This was seen in the example of Kumiko too. 
To go into the details of the issue, we formulated key questions in advance, although during the interview, the respondents were also given complete freedom to expand the issue and make their emphasis on it (this is where the semi-structured nature of our interview was revealed). Against the background of the pandemic, the main obstacle/barrier to successful communication in a multi-ethnic environment, according to the analysis of the obtained empirical material, is the lack of desire for communication, or moreover, its absence. Onboard, where space is already limited, intrusion of "someone else" exacerbates anxiety, increases the real risk of being infected, which in itself awakens an individual's special readiness and sensitivity to threat. Here, constant warning - "keep a physical distance" - raises subconscious fears and decreases the desire or motivation to contact others.

Unfortunately, in the frameworks of the qualitative research it was not possible to gather enough materials in this direction (separately quantitative research is needed for this), although according to the obtained data the mentioned fear and anxiety were especially visible while flying in a certain direction, i.e., during communication with passengers of certain nationalities (as a rule, on certain flights passengers of one of the national groups predominate). As a Georgian respondent, Mariam points out: "there are flights when a special problem arises while boarding and this process takes a longer time ... when passengers become particularly aggressive, they get irritated if a stranger sits next to them and they ask us to move to a free place ... and often it is impossible due to the configuration of seats in the plane." The calmest flights even in the pandemic conditions, as flight attendants confirm, remain flights in the direction of Japan and Korea. Flights are also calm in the direction of China where most passengers are Chinese themselves.

As it is seen, different approaches and attitudes towards the pandemic in different cultures were revealed in the process of interviewing. In addition to the abovementioned differences, during the interviews, the respondents showed different attitudes towards the Covid-19 vaccine. Even though we had no questions concerning this issue, our Western respondents, unlike Japanese, Korean or Filipino respondents, mentioned the vaccine several times, which they hoped would soon be developed. It may be a coincidence but it is a fact that none of our Eastern respondents mentioned the vaccine. Just on the contrary, during the conversation, some of them mentioned that some things are above human strength and are beyond our control. In our opinion, even the general picture formed against the background of Covid showed that in the cultures where people admire nature, accept it as God's creation, and obey it (Submissive orientation cultures), they display, as a result, more adaptability to the Covid situation, than in cultures where people try to possess and dominate it (Mastery orientation cultures) (Hills 2002: 5). 
The different approaches of the individualistic and collectivist cultures towards the pandemic are no less interesting. Fighting the pandemic in Eastern countries has been declared a collective responsibility, violations of general quarantine and rules (e.g., not wearing a mask) have been publicly punished and shamed in some Chinese cities, while most Western countries have placed responsibility on the individual and his/her attitude towards the problem. Consequently, as studies have shown, collectivist countries are more effective in combating pandemics than individualistic ones. ${ }^{4}$

A South Korean professor, psychologist Heejung Kim at the University of California, Santa Barbara, points out that in the pandemic conditions "a representative of the individualistic culture socially and psychologically isolates himself/herself from others ... it is interesting that in the USA we use the term "social distancing" while in Thailand for expressing the same recommended social behavior they use the term "physical distancing" which actually means restriction of only physical connection and thus deepening social closeness and unity as never before."

Here, in the same context, researchers today are actively talking about the essential differences between cultures, on the one hand, between strict, limited, morally identified (cultural tightness) societies and, on the other hand, free, unlimited, undefined (cultural looseness) societies. It is noteworthy that there is exactly this intercultural difference highlighted in Hofstede's last, sixth dimension, which deals with Indulgence versus Restraint (IVR), (Hofstede, Hofstede and Minkov 2010: 277-296). As the Covid pandemic has shown, some countries are much more vulnerable to fighting against the virus (e.g., USA, Brazil, Mexico) than others (e.g., Japan, Singapore, Taiwan) in terms of the infected and death data. Studies have confirmed that such a sharp difference is not due to the wealth of a certain country, the effectiveness of the medical field, the difference in age or climate, but due to at-first-sight simple, but the deeper intercultural difference - different readiness of the citizens of a specific country to obey/disobey the introduced rules and restrictions. ${ }^{6}$

\footnotetext{
${ }^{4}$ See The Importance of Culture in Societal Responses to COVID-19, Harvard Political Review, https://harvardpolitics.com/culture-response-covid-19/; How Different Societies React to Pandemic, University of California, https://www.universityofcalifornia.edu/news/how-different-societies-react-pandemics; How Cultural Differences Help Asian Countries Beat Covid-19, While US Struggles, https://www.voanews.com/covid-19-pandemic/how-cultural-differences-help-asiancountries-beat-covid-19-while-us-struggles (was available on 11.11.2020);

${ }^{5}$ See How Different Societies React to Pandemic, University of California, https://www.universityofcalifornia.edu/news/how-different-societies-react-pandemics (was available on 11.11.2020);

${ }^{6}$ See The relationship between cultural tightness-looseness and COVID-19 cases and deaths: a global analysis,
} 
It should be mentioned that at MIT Center for International Studies a panel discussion (in the frameworks of the so-called Starr Forum) was held on June 23, 2020, under the name of "When Culture Meets Covid-19". 7 The main topic of the discussion was the issue concerning different attitudes of cultures towards Covid-19. As it was mentioned during the discussion, in East Asian countries, compared with European countries, the importance of wearing a mask/face shield has not been questioned (for example, in China and Japan it has been accepted unconditionally), while in Western countries it was necessary to make a mandatory government call and several measures were taken by the state for this (constant advertising and calling, explaining why wearing a mask is necessary and obligatory, encouraging people by resort to politicians or celebrities (giving an example to wear a mask), etc.). The point is that individualistic countries have perceived this as a restriction on their rights and choices. ${ }^{8}$

Different approaches towards wearing a mask were illustrated even by the example of Qatar Airways. As the interviews revealed, the vast majority of European and American passengers protest wearing a mask on board, while Chinese and Japanese passengers unconditionally obey this rule. Consequently, the flights, as was mentioned above, are calmer and without conflicts in this direction. If we associate the high level of risk perception and anxiety with this trend of wearing a mask, we will see that people who are particularly anxious and perceive the threat of being infected with Covid more strongly, are less obedient to the rules of the company or, more generally to the rules/regulations of the state and the World Health Organization and they have certain complaints concerning wearing a mask.

Using a mask and a face shield, which, despite the protest, is obligatory for everyone on board, in its turn acts as a barrier to intercultural communication as it makes it impossible to establish an emotional connection with the interlocutor. A mask that covers most of your face and protects you from another person, i.e. from a potentially infected one, also disguises emotions, feelings, mimicry, and facial expressions. And in such a multiethnic workspace as Qatar Airways, non-verbal communication signals have crucial meaning in the process of communication.

https://www.thelancet.com/journals/lanplh/article/PIIS2542-5196(20)30301-6/fulltext; Why countries with "loose", rule-breaking cultures have been hit harder by Covid, https://www.theguardian.com/world/commentisfree/2021/feb/01/loose-rule-breakingculture-covid-deaths-societies-pandemic (was available on 18.03.2021);

${ }^{7}$ See When Cultures Clashes with Covid-19, MIT panelists examine the roles of social norms in countries' differing responses to the coronavirus pandemic, https://news.mit.edu/2020/when-culture-clashes-covid-19-0625

(was available on 11.11.2020);

${ }^{8}$ See A Cultural Perspective on COVID-19, https://www.chinausfocus.com/society-culture/acultural-perspective-on-covid-19 (was available on 11.11.2020); 
One of the important elements of non-verbal communication is the concept of territorialism, and attitudes towards it are different in different cultures (Hall 1959: 187, Hall and Hall 1990: 11). This implies that in some cultures personal space means a greater distance when interacting with others (for example, for English people this distance is a minimum 1.2 meters), while for other cultures this distance is relatively short (for example, 0.5 meters for Mexicans). Consequently, in some cultures, people come close to each other during direct contact, while in others such closeness creates discomfort and is considered a violation of personal space. In the pandemic conditions, universal importance was awarded to the invisible ring of protection of personal space of territorialism, and this distance, while being on board the plane, as we have mentioned, was determined by at least 1 meter. Keeping such a distance, in turn, significantly reduces the discomfort and dissatisfaction caused by the violation of personal space in a multi-ethnic environment. In this regard, our German respondent Alexandra noted the following: "new regulation on distancing protects me not only against the virus but also against the discomfort which I feel pretty often when I work on board, especially from the passengers. Most of them and some of our colleagues do not keep the appropriate distance and this kind of closeness is so irritating ... now they are forced to stand far away and have eye contact with you." But on the other hand, if for German Cabin Crew eye contact is a desired and proper form of communication, the same method is likely to be embarrassing for the representatives of Far or Middle East cultures (e.g. Japanese, Chinese, Qatari), as different perceptions connected with eye contact are mirrored by the culture. Thus, communication in pandemic conditions has some kind of danger in this regard too.

As for the question concerning the verbal association that arose while working in the conditions of Covid-19, received answers to this question also show that for some flight attendants it is a challenge with a more negative meaning ("stress", "tension", "fear", "risk" ...), for others this challenge is more positive ("unusual", "interesting" and "thought-provoking"). Karla, an Argentinian flight attendant, had especially interesting and poignant associations; she described this process as "turbulent"; according to her "the coronavirus is as frightening as the moment when you enter an unfamiliar turbulent zone, it scares you, but at the same time it makes you think about those values that maybe you have never thought about before."

Within the interests of our research, it was essential for us to discuss the issue of racial discrimination created against the background of the novel coronavirus and to illustrate the current challenge by the example of Qatar Airways. To the question of how noticeable the changes in attitudes towards Chinese and xenophobic attitudes were at the early stages of the coronavirus outbreak (at the time when the news about Wuhan was topical), we can answer 
by summing up the answers and concluded that the change in attitudes among the Cabin Crew was not noticeable (at least our respondents have not witnessed this kind of fact), but the same cannot be said about passengers. As many respondents noted, there were frequent cases when the passengers themselves protested the presence of (a) Chinese passenger(s) on the plane and demanded their strict isolation. There were some cases when they expressed aggression towards Chinese flight attendants. In this regard, the story of a Chinese flight attendant Bo is interesting: "Flight hours have been reduced for all of us, but I think it has especially affected the Chinese flight attendants ... I think it has not made me feel sad... There was so much aggression and hatred towards us, televisions and other media sources, especially at the initial stage of the virus spread, everyone broadcasted our wet markets and the unsanitary conditions there, discussing how we eat bats, snakes, dogs ... I am Chinese but I do not eat them, neither do my family members and friends, and have never eaten them..." Another Chinese respondent (who does not want to name himself/herself) mentions the following case: "when the flight ended and we said goodbye to the passengers, one kid while leaving the plane called me if I was really eating bats ... adults accompanying this kid, supposedly his/her parents, sniggered ... I am happy that there were people next to me (he/she means his/her colleagues - M.K.) who had different opinion and did not share this kind of stereotypical approaches". However, it is a fact that sometimes to some extent the inclination for categorization is present among the flight attendants too. For example, a flight attendant Ching from Hong Kong started her conversation with us by emphasizing that she is from Hong Kong and not from China, that they are different from each other as if it was humiliating for her to be Chinese.

The increase in discrimination based on nationality is also indicated by the fact that a flight attendant, Mei, from China, asked us during the interview to imagine ourselves in her position, and our country, accordingly, in the place of China, and speak about the difficulties of working in a multicultural environment caused by people's aggression on ethnic grounds, from this perspective. She also mentioned that she had never felt any kind of judgmental attitude from the colleagues, but despite this, she still had a feeling of embarrassment while interacting with them, especially at the initial stage of the virus outbreak. If we summarize the respondents' answers, we can say that if at the initial stage of the virus outbreak (especially in March and May) anxiety, fear and aggressive attitude towards Chinese passengers or flight attendants were noticeable, later on, starting from July, the feeling of anxiety decreased significantly and, therefore, the number of conflict situations on board also fell. Indeed, as Hofstede repeatedly points out, the elimination/avoidance of uncertainty and ambiguity is a prerequisite for 
anxiety removal, and the decrease of anxiety is directly correlated with an increase in tolerance (Hofstede, Hofstede and Minkov 2010: 187-235).

In conclusion, it was interesting for us to find out the respondents' evaluative attitudes, their predispositions, and predictions/expectations (negative or positive) about the post-pandemic arrangement of the world in a multicultural workspace, in which representatives of the individualistic and collectivist cultures meet each other daily, those who are oriented on different values, who have a different (high or low) index of uncertainty avoidance. Sub-questions that we asked in this context were as follows: What have they learned?; What kind of experience have they gained from the coronavirus pandemic?; What have they changed and reappraised?

As a result of working in the novel coronavirus pandemic conditions, all respondents unequivocally admit that they have improved their ability to orientate in difficult and unusual situations and to deal with problems, they have become even more tolerant and empathetic towards each other. By "being together" and "doing the same thing" in the risk group, they have developed a special feeling of unity. Cases of classification of colleagues by national mark and existence of so-called "group mafias" have now become insignificant and even ridiculous:

- "I think the pandemic showed us the value of human relationships... those minor conflicts which sometimes happen while being on board are somehow embarrassing and shameful ..." (Kristina from Macedonia);

- "When the coronavirus pandemic started my mother got scared by the fact that I was living with my Chinese colleague Yung... I think it is natural, my mother is always scared and tense because of my flights. She was calling me frequently and was asking me to avoid contact with her... a few times I felt so embarrassed as if Yung could hear our conversation. I was whispering to my mother not to mention the word "coronavirus" in her presence..." (Emilia, from Macedonia);

- "Flight attendants from all over the world have faced the greatest danger. Having contact with dozens of people, in spite of the reduced number of flights and passengers, still contains the highest risk for us... plus constant fear of losing a job, terrible expectation of being left without income... everybody is confused, though I have never felt this kind of mobilization and support before" (Carla, from Argentina);

However, it should also be mentioned that tolerance and empathy are not new for them. Flight attendants have developed these characteristics as a result of long-term work in a multicultural environment:

- "When I started work at Qatar Airways, almost 9 years ago, I was just 20 years old. I remember, when I saw Chinese flight attendants for the 
first time I was secretly looking at them and was thinking to myself: God, how can I differ them from each other?! I could not differ Chinese, Japanese, Korean, Vietnamese, even more, Indonesian, Thai or Filipino people from each other... today we are joking about this issue together, they cannot differ us, Europeans from each other... when we know nothing about others, we are afraid of them, we keep distance and unwillingly avoid contact with them ... I think, if I had met a Chinese passenger or a flight attendance for the first time in the pandemic conditions I would have been frightened, I would have assumed that he/she had been an infected, disgusting person and it is possible that I, like other passengers, would have protested their presence on board" (Milly/Milani, from France).

- "I am not surprised at negative attitude towards Chinese from some people and especially from children ... they do what they see... it is our fault, governments, journalists, society that is so xenophobic and discriminatory... lack of awareness is the origin of everything... it has not started now... we, flight attendants have been victims of various attitudes many times (including sexist) from people who do not even know us ... sometimes even in our own country"(Simona, from Romania);

As we can see, the facts of discrimination revealed while working onboard (mostly from passengers) are unacceptable for flight attendants and they explain it by being locked up, ignorant of other cultures, lacking daily communication with others. Working in a multicultural environment and interacting with others daily, especially interacting with colleagues, have naturally given them the openness, acceptance, cultural sensitivity that others, usually employed in a monoethnic environment, may not have. At the same time, working at Qatar Airways, as it was mentioned by several respondents, gave them not only acquaintances and just colleagues but also friends from almost all over the world.

As for the stereotypical approaches within the company, they still exist in the Covid-19 conditions, they have not disappeared anywhere and, therefore, still appear to be a hindering factor in the process of communication, although such rare and isolated cases cannot change the general picture, just on the contrary, they create the real expectation that the presence of such cases during the pandemic period will be further reduced in the intercultural environment as the importance of interconnection and cooperation will be reappraised to a greater extent. 


\section{Conclusion}

"Global threats require intercultural cooperation" - this is how Professor Geert Hofstede entitles the last subchapter of Chapter 11 of the fourth part of his book "Cultures and Organizations. Software of the Mind". $\mathrm{He}$ considers cultural threats to be the main threat to humanity and names intercultural cooperation as a crucial and main precondition for "survival" in the multicultural world (Hofstede, Hofstede and Minkov 2010: 426). At the same time, Hofstede hopes that global challenges such as global warming, ozone depletion, terrorism, arms and drug trafficking, etc. will force us to achieve yet non-existent global cooperation in the future.

Today, a new challenge for the world - the coronavirus pandemic which hinders the process of intercultural communication in all directions poses a new threat to globalization:

1. Predictions concerning the reduction of international trading within $13-32 \%$ in the conditions of protectionism regulations have been made by the World Trade Organization (WTO);

2. Incapability and inefficiency of global institutions have been highlighted: in the countries most affected by the virus - Italy and Spain - dissatisfaction has been expressed concerning the EU, which is already "burdened" with the Brexit processes, accusations have also been heard against the World Health Organization;

3. As soon as the pandemic started, the world's leading countries chose isolationist policies and closed their borders for the sake of national security, imposed strict restrictions on non-citizens, labor migrants and refugees, and delayed the issuance of student visas;

4. Cases of xenophobia and ethno-cultural racism have become more frequent. As shown in official documents of Human Rights Watch, not only anti-Asian but also anti-Muslim and anti-African racism and discrimination cases have been revealed ${ }^{9}$;

5. The travel and tourism industry has been halted, most airlines have reduced or completely stopped flights;

6. The Olympic Games and the European Football Championship have been delayed;

7. The Global film industry has been stopped;

8. International congresses and conferences have been cancelled.

Taking into consideration all this, most economic and policy analysts and experts of international relationships assume that the main characteristic of the post-pandemic/post-crisis world will be deglobalization. The world has

\footnotetext{
${ }^{9}$ See Human Rights Dimensions of Covid-19 Response, https://www.hrw.org/news/2020/03/19/human-rights-dimensions-covid-19-response (was available on 24.10.2020).
} 
seen it clearly that in the conditions of globalization regional/local infection has been rapidly spread globally (i.e., the pandemic with its essence is the result of globalization). However, on the other hand, it has also become clear that only global technological achievements and mechanisms can bring innovations in the medical field, including real and even the only possibility of defeating the virus. Therefore, in our opinion, the adequate response to the new challenge of the world should not be deglobalization, but even more globalization, "neo-globalization", i.e., the development of joint strategic plans and mechanisms, strengthening economic, political, and cultural links/chains.

On the example of the study of specific situational analysis (so-called cases) of Qatar Airways, we saw the examples of aggravated negative cases against the background of Covid-19, examples of racism and xenophobia, which, of course, hinder the process of successful communication and respond directly to the current world events. However, we can also say that the virus that does not recognize national borders, does not differentiate between nationality, race or religion, also has another side - it can make us think about the importance of a common struggle, about the advantage of standing together and acting together.

The confirmation of this positive influence is the conclusion made by analyzing the data obtained through the qualitative research, which is the opposite of the hypothesis expressed at the beginning of the research. In particular, multicultural connections and daily interaction with groups having other cultures significantly increase opportunities for cooperation, which, in times of crisis, not only hinder the process of interaction between different cultures but, on the contrary, increase intercultural acceptance and the level of sensitivity.

The Cabin Crew of Qatar Airways, despite their sometimes opposite to each other reactions towards the novel coronavirus, which is caused by their cultural differences, have developed more trust, and in some cases, they have reappraised previously non-existent relationships and mutual respect. The attitude of "we are in the same boat", the feeling of equality, empathy, and more solidarity have strengthened.

In our opinion, multicultural companies such as Qatar Airways are one of the best ways to stop the process of "forced deglobalization" and to achieve a peaceful and harmonious coexistence of a new, post-pandemic world.

\section{References:}

1. Douglas, M. (1978). Cultural Bias. No. 35. London: Royal Anthropological Institute

2. Douglas, M. \& Wildavsky, A. (1982). Risk and Culture. Berkeley; Los Angeles; London: University of California Press 
3. Douglas M. (1992). Risk and blame: essays in cultural theory. London \& New York, NY: Routledge, https://monoskop.org/images/1/1d/Douglas_Mary_Risk_and_Bla me_Essays_in_Cultural_Theory_1994.pdf

4. Hall, Edward T. (1959). The Silent Language, Doubleday \& Company, INC., Garden City, New York

5. Hall, Edward T, and Hall, Mildred R. (1990). Understanding Cultural Differences. Yarmouth, Me: Intercultural Press

6. Hills, M. D. (2002). Kluckhohn and Strodtbeck's Values Orientation Theory. Online Readings in Psychology and Culture, 4(4). https://scholarworks.gvsu.edu/cgi/viewcontent.cgi?article=1040\&con text $=$ orpc

7. Hofstede, G., Hofstede G. J., Minkov, M. (2010). Cultures and organizations: software of the mind, Intercultural cooperation and its importance for survival, third edition, https://eedu.nbu.bg/pluginfile.php/900222/mod_resource/content/1/G.Hofsted e_G.J.Hofstede_M.Minkov\%20$\% 20$ Cultures\%20and\%200rganizations\%20$\% 20$ Software\%20of\%20the\%20Mind\%203rd_edition\%202010.pdf

8. Kluckhohn, F. R., \& Strodtbeck, F. L. (1961). Variations in value orientations. Evanston, Illinois: Row, Peterson

9. Guidance for Cabin Operations During and Post Pandemic Edition 4 08 Sep 2020, https://www.iata.org/contentassets/df216feeb8bb4d52a3e16befe9671 033/iata-guidance-cabin-operations-during-post-pandemic.pdf

10. Guidance for Crew Health Precautions During Pandemic Edition 1 28 May 2020, https://www.iata.org/contentassets/df216feeb8bb4d52a3e16befe9671 033/iata-guidance-crew-health-precautions-during-post-pandemic.pdf

11. The Importance of Culture in Societal Responses to COVID-19, Harvard Political Review, https://harvardpolitics.com/cultureresponse-covid-19/

12. How Different Societies React to Pandemic, University of California, https://www.universityofcalifornia.edu/news/how-different-societiesreact-pandemics

13. How Cultural Differences Help Asian Countries Beat Covid-19, While US Struggles, https://www.voanews.com/covid-19-pandemic/howcultural-differences-help-asian-countries-beat-covid-19-while-usstruggles

14. The relationship between cultural tightness-looseness and COVID-19 cases and deaths: a global analysis, 
https://www.thelancet.com/journals/lanplh/article/PIIS25425196(20)30301-6/fulltext

15. Why countries with "loose", rule-breaking cultures have been hit harder by Covid, https://www.theguardian.com/world/commentisfree/2021/feb/01/loos e-rule-breaking-culture-covid-deaths-societies-pandemic

16. When Cultures Clashes with Covid-19, MIT panelists examine the roles of social norms in countries' differing responses to the coronavirus pandemic, https://news.mit.edu/2020/when-culture-clashes-covid-19-0625

17. A Cultural Perspective on COVID-19, https://www.chinausfocus.com/society-culture/a-cultural-perspectiveon-covid-19

18. Human Rights Dimensions of Covid-19 Response, https://www.hrw.org/news/2020/03/19/human-rights-dimensionscovid-19-response 